\title{
Topical Collection: The EPDS: Thirty Years On
}

Special Guest Editor: John Cox

Professor Emeritus Keele University, UK

BM BCh DM (Oxon) FRCPsyh FRCP

23, New Court Lnsdown Rd Cheltenham GL50 2 JG

(C) Springer-Verlag GmbH Austria 2017 